\title{
O Gravador, a Preguiça e o Viajante
}

The Engraver, the Sloth and the Traveler

MATHEUS SILVEIRA FURTADO

Universidade de Brasília (UnB), Brasília DF, Brasil

\section{RESUMO}

objetivo deste artigo é apresentar, a partir da análise de três figuras, de que maneira o contexto e a singularidade, na produção de "Bestiário" de Gabriel Soares de Sousa, da coleção dos Cem Bibliófilos do Brasil, intercalam camadas de temporalidade e significados, que flertam com conceitos entre livro de artista, narrativa visual, ilustração de enciclopédias e relato de viagem, o que faz desse livro uma experiência limite.

\section{PALAVRAS - CHAVE}

Representação, preguiça, imaginário, Marcello Grassmann, gravura.

\begin{abstract}
A B S T R ACT
The objective of this article is to present, from the analysis of three figures, how the context and the singularity, in the production of "Bestiário" by Gabriel Soares de Sousa, from the collection of the One hundred Bibliophiles of Brazil, interlayer layers of temporality and meanings, who flirt with concepts such as artist's book, visual narrative, illustration of encyclopedias and travel stories, which makes this book a limit experience.
\end{abstract}

\section{KEYWORDS}

Representation, sloth, imaginary, Marcello Grassmann, engraving. 


\section{Introdução}

Sendo um dos primeiros livros escritos no território brasileiro, em pleno século XVI, "Bestiário - Trechos do Tratado descritivo do Brasil", o manuscrito do relato das viagens de Gabriel Soares de Sousa foi publicado em Portugal após seu retorno, em 1587. A originalidade de seu texto acerca da fauna e flora observadas garantiu com que mesmo quatrocentos anos depois, em 1958, a reconhecida Sociedade dos Cem Bibliófilos do Brasil o escolhesse como um dos volumes de valor para compor a sua coleção. Além disso, convidou o gravador Marcello Grassmann para desenvolver um papel maior do que o de um ilustrador, e sim o papel de realizar uma narrativa conjunta àquela do texto, por meio de suas imagens. Quando editado pelos Cem Bibliófilos e ilustrado por Marcello Grassmann é, pela especialidade de sua conjuntura, um espécime único que mistura temporalidades, propósitos e significados.

Tal como "Guilherme - o Marechal, de Georges Duby"; "O nome da Rosa", de Umberto Eco, experiências limite entre ficção e historiografia, aqui este livro é também entendido como um exemplar de trabalho transdisciplinar. Ultrapassando a ideia de junção de disciplinas, vai além da multidisciplinaridade. E então é semelhante àqueles que não apenas realizaram misturas entre tipologias e gêneros da literatura, mas que de fato se apresentam com e conexões tão complexamente interligadas que é impossível perceber onde começam e terminam essas possíveis separações do conhecimento. No caso, o objeto "Bestiário" é mais um desses modelos. Entre objeto de arte e exemplar de relato de viagem. É também experiência limite de narrativa fantástica e descrição de observação protoenciclopédica, característica comum dos Bestiários, um dos subgêneros dentre os livros laicos, durante a Idade Média. E da mesma forma em que há ricas decorações para os manuscritos medievais, a ilustração de Grassmann, serve para além de recurso demonstrativo. Ela "ilumina" o texto. Ele faz uma narrativa própria, já que a molda com as imagens.

Essa organização luxuosa dos trechos do "Tratado Descritivo do Brasil" possui facetas que se consolidaram, pela própria realização da Obra, e que de uma maneira única, também se constroem na medida em que analisamos mais de perto o papel de cada um dos protagonistas envolvidos em seu processo de produção. Apresenta a noção de ilustração enciclopédica, e também flerta com o conceito de livro de artista pela valiosa contribuição do renomado gravador paulista, que pelas imagens impõe uma narrativa; é relato de viagem, praticamente um gênero próprio da literatura na Era Moderna, porque Gabriel Soares de Sousa o escreve para tanto, em uma lógica de encantar o leitor. É um bestiário atemporal, pois foi produzido e reapropriado por uma série de temporalidades.

Para demonstrar a especialidade desta obra sensível e complexa, três figuras importantes são destacadas. Sejam produtores ou integrantes deste livro, personagens ou narradores (narrador que descreve aquilo que observa, e narrador que esclarece/ilumina aquilo que lê) eles se apresentam como elementos fundamentais de toda uma conjuntura que, desde a escrita no século XVI até encomenda da edição por parte da Sociedade dos Cem Bibliófilos, se estabeleceu acerca da fauna, flora e povo descritos nos primeiros anos de ocupação do Brasil. 


\section{0 viajante}

Gabriel Soares de Sousa, viajante, aventureiro e observador português. Nomeadamente produtor de uma das primeiras obras, não apenas a serem escritas em território brasileiro, mas seguramente uma das vanguardistas no que tange a descrição de sua terra, fauna, flora; e dos hábitos alimentares do, à época, povo brasileiro.

Produzido como resultado de suas expedições aos rincões do sertão brasileiro em 1580, "Bestiário", ou o "Tratado Descritivo do Brasil" consiste de mais uma das conhecidas narrativas de viajante, gênero tão característico na Era Moderna. 0 livro se destaca frente aos seus similares por uma diversidade de características. A preocupação com as descrições das bestas, mesmo as que habitam o espaço do Imaginário; o fato, não tão comum para relatos de viagem, de que há observações criteriosas acerca do interessante comportamento dos novos animais que ali se encontram; uma série de observações gastronômicas em relação aos sabores dos bichos, que ele pôde experimentar cozinhar, fritar, assar entre outros variados e curiosos processos de preparação do alimento; e não menos importante há esta última característica, o ideal narrativo conjunto das imagens de Grassmann e a escrita de Sousa, que o destaca frente aos demais textos de viagem.

0 autor/observador é responsável pela produção de certo imaginário assombroso para com o que ele descreve. Um quadro mental, elaborado pela narrativa do viajante, transporta o leitor não apenas para o inóspito cenário, que a ambientação brasiliana representa, mas principalmente para a ferocidade dos animais com os quais ele topou pelo caminho. É interessante, no entanto, dizer que os textos e a produção literária desse "viajante-observador" são considerados por certos teóricos da literatura e historiadores portugueses, como rudes, primitivos, essencialmente diretos. Algo que facilita a associação direta das anotações de Sousa com a perspectiva descritiva direta que apresentam vários dos bestiários medievais.

Há então, na obra uma perspectiva dicotômica, que a insere numa lógica narrativa de produção característica mais marcante nos bestiários medievais, do que na literatura e viagem. Apresentando para o leitor uma espécie de rigor protocientífico na observação e para as descrições comportamentais dos animais, ao mesmo tempo em que possui um elemento de moralização para com as bestas e aves que interpreta. Existe "um quê" de assombro na escrita de Gabriel Soares de Sousa. 0 que termina por ser de fato revelador tanto do que ele autor/observador pensa acerca daquilo que vê, quanto uma perspectiva geral daquele Imaginário (descrito por Le Goff em seu “O Imaginário Medieval") como vigente nas sociedades em que Sousa viveu e produziu seus trabalhos. Uma mentalidade que ainda como demonstra Jérome Baschet em "A Civilização Feudal", ainda é essencialmente carregada dessa Idade Média, quando se depara com o Novo Mundo:

Existe então uma continuidade entre o desenvolvimento da Idade Média Central e a dinâmica reencontrada do fim da Idade Média, de modo que o elã que conduz à conquista é fundamentalmente o mesmo que aquele que vemos em marcha desde o século XI. A colonização ultra-atlântica não é o resultado de um mundo novo, nascido sobre o húmus em que se decompõe uma Idade Média agonizante [...] é a sociedade feudal [...] que empurra a Europa para o mar [...] Uma Europa dominada 
ainda por um longo tempo pela lógica feudal, com seus atores principais a Igreja, a monarquia e a aristocracia [...] não uma Europa saída transfigurada da crise do fim da Idade Média e agora portadora das luzes resplandecentes do Renascimento [...] (BASCHET, 2006, p. 274-275).

Dessa forma é clara a associação com os bestiários medievais. O autor produz, pela maneira em que monta o relato, certa lógica narrativa extremamente semelhante da que é encontrada nesses códices medievais. Moralização surge pela observação; comparação pela seleção do que descrever; e fascinação, pelo método que se vale para sua escrita. Apenas como um exemplo: formigas (Figura 1) e porco espinho são alguns dos animais mais retratados pelos bestiários, e aparecem, à sua maneira, também no Bestiário do Brasil.

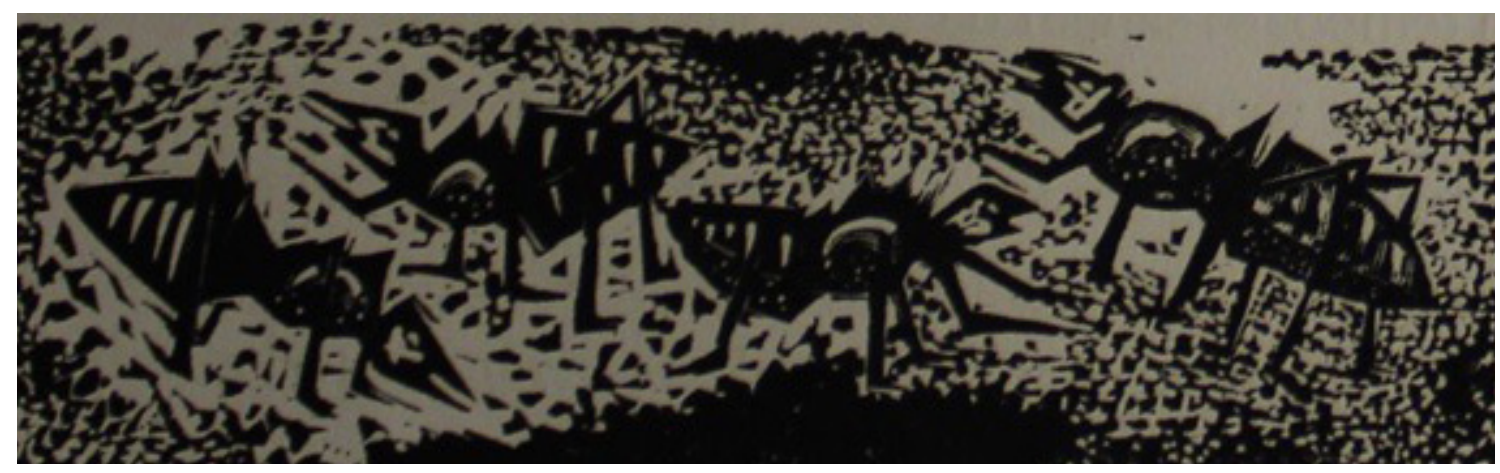

Figura 1. - Marcelo Grassmann, sem título, 1958. Xilogravura Recorte de fotografia da página 86. "As Formigas vermelhas". Fonte do autor.

[...] Formigas mui [sic] estranhas as quaes [sic] os índios chamam goajugoaju, as quaes [sic] são pequenas e ruivas, e mordem muito [...] matam as baratas, aranhas, e os ratos, e todos os bichos [...] entram-lhes pelos olhos, orelhas, e narizes, e pelas partes baixas [...] e quando correm uma casa toda passam por diante a outra, onde fazem o mesmo e a toda uma aldêa [sic]; e são tantas essas formigas, quando passam, não há fogo que baste para as queimar [...] e matam tambem [sic] as cobras que acham descuidadas [...] tratam e mordem tão mal que as acabam (SOUSA, 1958, p.86).

O que se percebe em ambos os casos, há observação e fascinação. Mas no "Tratado Descritivo do Brasil" tem-se o assombro como o principal elemento para demarcação da ferocidade com que esses cruéis animais aparentam possuir nesse imaginário europeu do viajante, que agora se depara com o novo e diferente mundo. Um mundo de natureza dura e selvagem, consequentemente gerador das vorazes formigas brasileiras, a moralização advém desse assombro e da marcação de ferocidade. Pela experiência relatada no trecho, o encontro 
com estas formigas nunca é, para nosso espantado narrador, fortuito e não possui a mesma característica do exemplo moral de auxílio e trabalho comunitário que a contrapartida europeia do inseto dá pelos bestiários medievais.

O que diz todo esse desenvolvimento sobre o viajante? Há uma conduta na maneira da escrita. Mais do que gerar um engajamento direto, ele se propõe a cativar e impressionar o seu leitor, talvez com o ato heroico de fazer a viagem? De se encontrar com tais criaturas? Com certeza é uma percepção da construção de uma ponte entre o novo e o velho mundo. Afinal, não é para esses propósitos que os relatos de viagem eram feitos? Mas aqui há um grande porém. Ele usa um bestiário como a ferramenta de contato e confronto. São suas dinâmicas e sua lógica, que fazem dele um quase gênero próprio na tipologia de livros medievais, que o tornam um diferencial único, e que regem a maneira como o viajante conduz o seu texto. Um bestiário observa e interpreta os animais, ele não é um mero apanhado de curiosidades sobre bestas, aves e peixes. É também em sua essência um conjunto moralizado de normas sociais, os homens devem ter lições pelo exemplo dos outros animais gerados por Deus. Apesar de possuir uma carga semântica não religiosa, uma moral também se exprime nos relatos de viajantes, é um elemento intrínseco da tipologia, a singularidade de Gabriel Soares de Sousa é que ele educa seu próprio olhar para com o animal que pretende observar e descrever, e coloca seu assombro, como uma característica feral, para elucidar aquilo que o impacta.

\section{0 Gravador}

Marcello Grassmann, artista brasileiro e gravador renomado. Foi um dos principais expoentes da gravura nacional, e um aficionado pela Idade Média, não somente como interesse curioso, mas sim como objeto de estudo e trabalho. Percebendo a trajetória e a obra do artista paulista, não foi sem motivos que a Sociedade dos Cem Bibliófilos do Brasil o convidou e escolheu para fazer as ilustrações da sua versão de luxo, de colecionador de "Bestiário". Ao perceber as lógicas de conexão profundas entre o trabalho desenvolvido pelo viajante, com os bestiários, e o Imaginário que preenche as temáticas das gravuras de Grassmann, os Cem Bibliófilos desenvolveram um papel chave na significação de ambas as construções através do tempo.

Em bestiário podemos entender de maneira clara as percepções que levaram ao ideal de escolha para o gravador. A sua estética, muitas vezes repleta de hachuras, de seres e formas mistas, grotescas, em muito complementam o tom de assombro que a narrativa de viagem traz ao trabalho do viajante. As suas xilogravuras desenvolvidas, encomendadas pelo grupo de colecionadores de livros, moldam um cenário ainda mais rico de associação entre bestiários, o do Brasil e outros que descendem diretamente do "Physiologus", primeiro modelo de manuscrito para um bestiário (texto mais próximo de uma zoologia, fantástica e real) medieval.

A fantasia é um ponto chave para a compreensão do livro ilustrado por Grassmann. Sua preocupação e referência constante ao Medievo fizeram com que ele, artista, do século XX, valorizasse as perspectivas de encantamento da narrativa. Tendo maior conhecimento sobre o país e sua fauna e flora (principalmente pela história), ele poderia ter ignorado esses místicos elementos que aparecem em bestiários, afinal, todos os animais seguem ali descritos, os que existem e os que 
não. No entanto ele não o faz, ele toma a rota da incerteza, e grava os bichos: insetos, peixes, bestas e pássaros; na maneira em que o escritor português, do século XVI, os descreve. Selvagens, brutos, assombrosos.

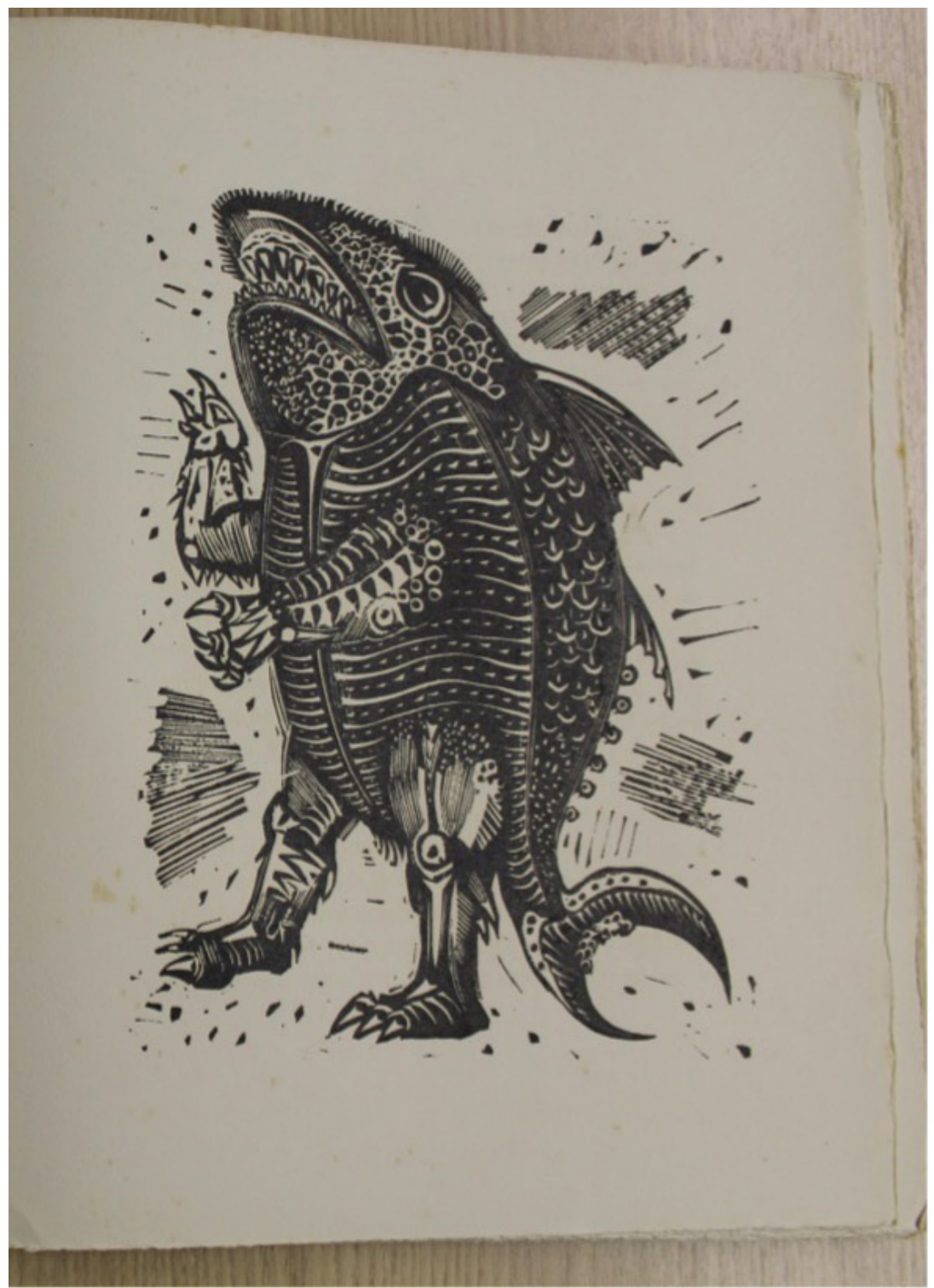

Figura 2. - Marcelo Grassmann, Homem marinho, 1958. Xilogravura. Fotografia da página 101. Fonte do autor.

A imagem do Homem marinho (Figura 2) apresenta precisamente esse caráter de valorização do imaginário presente no livro. Não descrições dele, apenas do que o ataque dele pode provocar, e que a criatura possui um corpo híbrido, mas sem detalhamentos sobre "qual metade" corresponde a o que. Essa ambientação fantástica é precisamente uma das melhores pontes de 
conexão que a trajetória de Grassmann permite com o contexto geral de produção do objeto. 0 artista tinha como uma das suas preocupações principais, essa representação das formas mistas, de corpos disformes, como escreveu Priscila Rufinoni (2007) em sua tese "Quimeras da Modernidade”.

Obviamente as concepções conceituais não foram o único motivo para a escolha do artista, como informam Maria de Fátima Medeiros (2016) e Vicente Martínez (2008) em seus respectivos trabalhos "O estudo da coleção de livros da Sociedade dos Cem Bibliófilos do Brasil" e "A modernidade do livro de arte brasileiro" em que discutem a proximidade dos livros da coleção com os conceitos acerca do tipo Livro de Artista, e como os objetos/livros da Sociedade dos Cem Bibliófilos se relacionam, distanciam e aproximam desse conceito. Existe um papel significante do envolvimento do artista na produção de tais objetos, de luxo, de consumo. Além de um texto apreciado, a riqueza de gravuras feitas por um artista reconhecido, valoriza o código de pertencimento e validação social que possuir tal objeto proporciona. Como demonstram Douglas e Isherwood (2004), em seu renomado livro “o Mundo dos Bens”, possuir algo que garante o papel de validador é em si mesmo possuir poder materializado. Os livros há muito têm sido estudados pela historiografia, enquanto objeto de poder. E tendo, como descreve Eco (1989) em “Arte e Beleza na estética” não apenas pela posse do objeto, mas também pela compreensão do código, é que há uma expressão das lógicas de poder nele envolvidas.

Assim há ainda outro papel desenvolvido na ilustração do texto por parte do artista. Ele esclarece o discurso trazido pelo tom e assombro e fantástico. Carrega a Imagem como ferramenta para iluminar o relato do viajante português. Teria essa sido uma camada de pensamento feito pelos Cem Bibliófilos para a escolha do artista? Ou apenas o seu eterno retorno para temáticas e figuras medievais, bestas e carrancas, motivado a encomenda das imagens? É claro que não é possível conceber apenas um único motivo para o que foi feito.

A noção clara dessa estética bestial dos trabalhos do artista; o seu fascínio pela Era Medieval, e também pelos bestiários como objeto de admiração; a compreensão de uma forma de arte que valoriza a materialidade, ao ponto de queimarem as matrizes, para que não fossem feitas demais reproduções, tal como é a gravura; não são meras características, mas sim parte de um código de significação maior para o conjunto da obra de Grassmann.

\section{A preguiça}

A besta - Bradypodidae (família das preguiças), mamíferos e nativos do Brasil. À época presentes em vasta maioria do território brasileiro. Não há uma certeza clara acerca de quais das espécies de bicho-preguiça Gabriel Soares de Sousa pode ter encontrado em suas numerosas idas e vindas, durante o processo de escrita do seu “Tratado Descritivo do Brasil”. Mas uma coisa é certa: o assombro que ele teve ao se deparar com o animal.

Nestes matos se cria um animal mui estranho a que os índios chamam Ahy, e os portugueses preguiça, nome certo mui [sic] acommodado [sic] a este aninal [sic], pois não há fome, calma, frio, água, fogo, nem outro perigo que veja diante, que o faça mover uma hora mais que outra (SOUSA, 1958, p. 56-58). 
Entre as muitas descrições animais do autor, a preguiça detém uma das mais extensas, ocupando três páginas do texto, incluindo a imagem. É curioso pensar que no universo de escolhas e possibilidades para a montagem de "Bestiário" a escolha da preguiça tenha sido feita. O estranhamento é tal, que em sua passagem final não há descrição nem relato de consumo de sua carne, característica presente em muitos outros relatos, o elemento gastronômico é sempre deixado para a última parte da descrição.

[...] acontece muitas vezes tomarem os indios [sic] um destes animaes [sic] e levaremn'o [sic] para casa, onde o tem quinze e vinte dias, sem comer cousa alguma, até que de piedade o tornam a largar; cuja carne não comem por terem nojo d'ella [sic] (SOUSA, 1958, p. 56-58).

O que se percebe pelo trecho é que tal estranheza gera o bicho, que nem os indígenas a consomem, principalmente por nojo. Para o viajante então, se mesmo os nativos, que deveriam terse habituado com o animal, (possuem uma postura diferente em relação ao comportamento para com outras bestas), a preguiça era única e menos agradável ainda. Um animal inédito, que nunca havia sido visto antes. Isso se justifica pelo fato já sabido de que esses animais são encontrados exclusivamente na América do sul, ou seja, seu primeiro encontro é de fato com o encontro de novos territórios.

Por essa razão, de estranhamento claro e desconhecimento nítido, ele se vale de elementos do arcabouço visual que já possuía, para descrição. A besta é "felpuda como cão d'água”, possui “dentes e gadelhas como um gato" além de ter "braços e pernas longos com muita lã”. (SOUSA, 1958, p. 56-58).

Pela gravura de Grassmann podemos perceber uma série dessas características na imagem. Tanto para ele, quanto para nós, leitores contemporâneos, o conhecimento da forma e do comportamento de uma preguiça pode ser caracterizado como naturalizado, aprendido, e é nesse ponto que se concebe a compreensão da inventividade na escolha dos Cem Bibliófilos. 0 Artista traz sua preguiça (Figura 3) com feições extremamente marcadas, entre felina e ave de rapina. O olhar retorna direto ao observador/leitor, ele também nos observa. Seu pelo "lã" como mostra Sousa, é vasto e emaranhado, e as hachuras e pontas muito bem traçadas dão exatamente essa noção.

É interessante notar que apesar da menção clara do autor para o Cão d’água português, essa não parece ter sido uma das referências de Grassmann ao produzir a pelagem da sua preguiça. Ela possui vasta pelagem, mas não parece ser aquilo que é descrito para o cão “ondulada e comprida". Ela é emaranhada e se estende por todo o corpo deste bicho que olha direto para o observador.

O animal é apresentado no contexto em que foi muito descrito: atrelado a uma árvore, novamente outra característica muito importante da imagem, sendo o único animal, dentre todos, que aparece localizado em uma referência clara ao seu hábitat - árvores. Pela descrição de Gabriel Soares de Sousa entre árvore e preguiça ambas podem ser vistas como uma só entidade, o 
bicho não iria ao chão, nem mesmo com o mais forte vento. E seja pela contraposição ao discurso narrativo escrito, seja pela tradição de sua estética, Grassmann traz movimento para a figura, ela não aparenta estar estática, sua posição e curvatura dão mais do que angulações, traduzem fluidez; característica que não pertenceria ao bicho preguiça de Sousa "que não se move nem com a maior das fomes". 0 que demonstra a escolha que o gravador possui no momento em que se propõe a elucidar o texto.

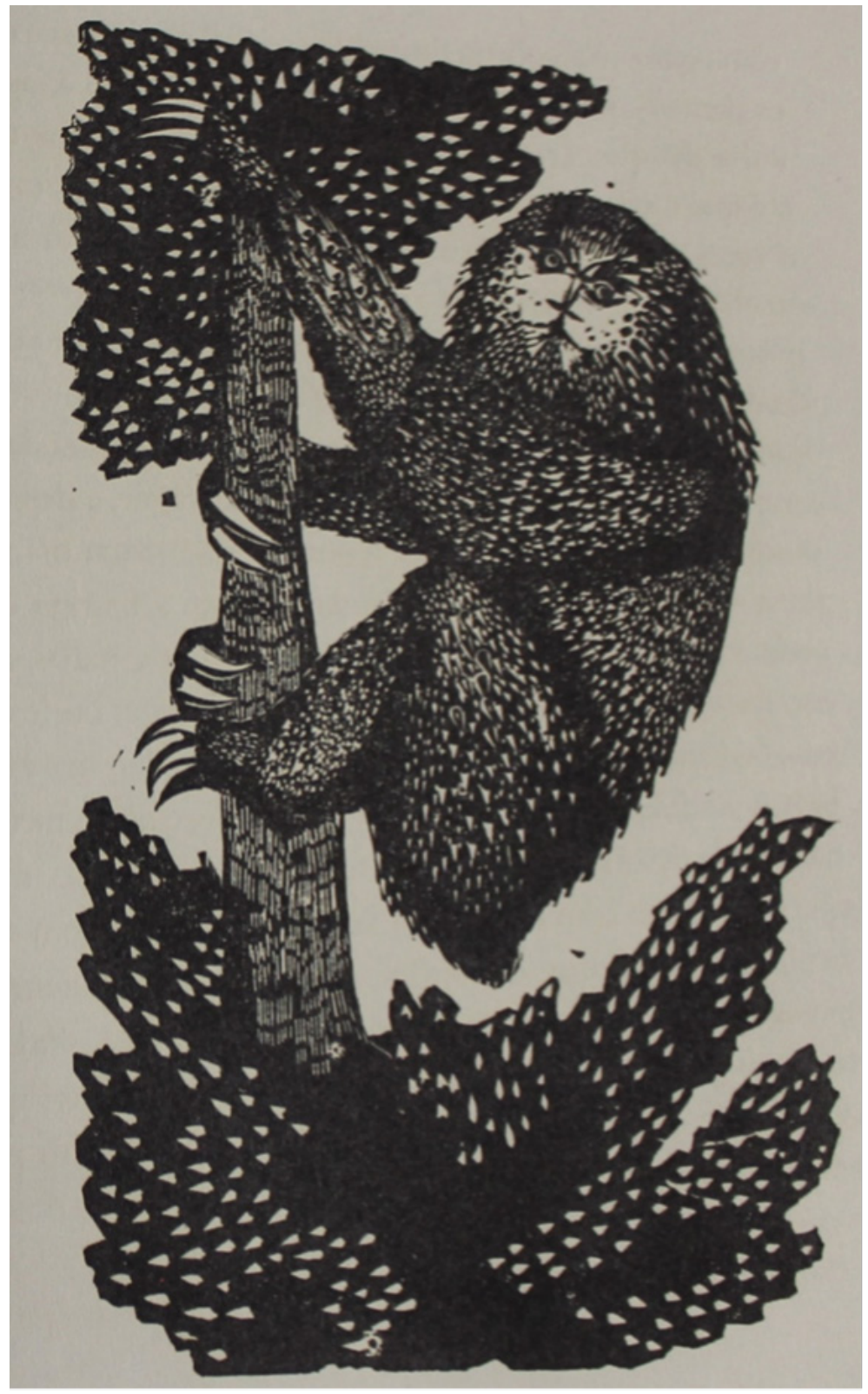

Figura 3. - Marcelo Grassmann, sem título, 1958. Xilogravura. Fotografia da página 57 - a preguiça. Fonte do autor. 


\section{Considerações Finais}

A preguiça é um dos muitos exemplos que podem ser utilizados para compor a ideia de que há também uma narrativa imagética inserida em “Bestiário”. Essa lógica é proposta pelo ilustrador que faz duplo papel, gravador-iluminador, do imaginário de um tempo, além de trechos de um texto, e da imaginação de um homem, além do apelo de relato de viagem.

Tudo leva a crer que de toda a coleção, os exemplares do "Tratado Descritivo do Brasil”, possuem uma perspectiva de camadas semióticas de significação. Não há um único nível importância para o objeto material livro (para possuí-lo); para as ilustrações de Grassmann; para o texto de Gabriel Soares de Sousa e nem para a preguiça ativa e flutuante que se apresenta no texto. 0 contexto permite considerar alguns elementos chaves para a produção do artista. A partir deste trabalho, que parece ter sido único em estética, e pela queima das matrizes, não foi possível que figurasse novamente em toda a trajetória do artista.

O artista realizou mais que uma ilustração daquilo que leu. Ele narra pictoricamente, produz uma intervenção de tamanho poder significativo na obra que a transforma e traduz sua própria narrativa. O Gravador faz dos trechos escolhidos, um todo que é livro e que também se aproximaria conceitualmente de livro de artista. É curioso pensar nesta associação, mas ela é possivelmente lógica, se desconsiderarmos o papel dele enquanto iluminador do código escrito, o seu uso desse arcabouço de imagens e recursos estéticos passa a ser desconexo. E de fato o foi, é notória a repetição aleatória de algumas das imagens dos animais e seres deste livro, que apareceram em outras séries produzidas ${ }^{1}$. Essas imagens, quando vistas fora deste contexto do livro, parece óbvio dizer, mas não carregam esse valor de representação do imaginário. Elas não são elementos que remetem diretamente ao medievo, como os cavaleiros e donzelas que Grassmann fez ao longo de sua carreira, e ainda assim elas ressurgem, mas num outro contexto. 0 que demonstra ainda mais a especial relação entre o trabalho das imagens e o texto escrito.

Sobre fazer de uma obra um todo, para tanto, a respectiva edição do livro só é todo em seu contexto de objeto de colecionador (íntegro por figurar em uma coleção). Esse elemento é também importante de ser lembrado, pois ele compõe um quadro social de produto e consumo, o que termina por justificar a que propósito servem as narrativas elaboradas. Ao restrito grupo dos bibliófilos, que originalmente fariam uma contemplação clara dos objetos que haviam encomendado.

O animal aqui apresentado com detalhes é mais uma das figuras, como dito anteriormente, que demonstram a especialidade e singularidade da relação: artista - determinado tempo no passado - objeto de encontro. Há mais do que noções de interesse pela Idade Média. Há verdadeiras formas de Longa Duração, na narrativa escrita e descritiva, há também moldes da ideia de Sobrevivência, como utiliza Didi-Huberman, na narrativa Imagética; e há uma transdisciplinaridade quando se olha com atenção sobre o objeto material livro, agora reapropriado.

1 Em especial algumas das gravuras para os insetos, abelha e mosca com mais ocorrência ao longo do tempo; a gravura referente ao homem marinho com eventuais outras aparições, a gravura do javali e com pouca frequência gravuras para mostrar os répteis - jacarés e tartarugas. 
Olhar para essa curiosa Preguiça agitada de Grassmann é, em síntese, mais do que visualizar a ilustração de um texto. É permear-se por essas camadas de temporalidade tão bem constituídas. O tempo do Imaginário; outro do viajante; o do gravador-iluminador, o do presente (observador e leitor); e o tempo próprio da Preguiça. Esse objeto, em sua singularidade transdisciplinar, faz de todo o seu processo de leitura uma experiência com múltiplas potencialidades de narrativa para aquele senta e o lê, há uma vivência ampla. Há o aspecto de valor textual, recurso essencial para o entendimento da mentalidade que viajou, escreveu, publicou estas observações. Há a linha de imaginário contemporâneo, traduzido pela narrativa visual das gravuras-iluminuras do artista paulista. E há o entendimento dos colecionadores, que por valorizarem esses elementos, proporcionaram para a posteridade um artefato, um bestiário atemporal e transdisciplinar. 


\section{Referências}

BASCHET, J. Liberdade Artística e inventividade iconográfica. - Práticas e funções das imagens. In: A Civilização Feudal. Ed. Globo. SP. 2006.

Aberdeen Bestiary - Special Colections Centre, University Library, Aberdeen. Disponível em: <https://www.abdn.ac.uk/bestiary/ms24/f24r>. Acesso em: 15 julho 2020.

DIDI-HUBERMAN, G. A imagem sobrevivente. Ed.: contraponto. RJ. 2013.

DOUGLAS, M.; ISHERWOOD, B. 0 mundo dos Bens. Ed.: UFRJ. RJ. 2003.

LE GOFF, J. 0 imaginário medieval. Ed.: Estampa. SP. 1994.

MARTINEZ, V. A modernidade do livro de arte brasileiro: a Sociedade dos Cem Bibliófilos do Brasil na coleção de obras raras da UnB. In: ENCONTRO NACIONAL DA ASSOCIAÇÃO NACIONAL DE PESQUISADORES EM ARTES PLÁSTICAS, 17., 2008, Florianópolis. Anais.... Florianópolis: [s.n.], 2008. Disponível em: <http://anpap.org.br/anais/2008/index.html>. Acesso em: 10 fev. 2020.

MEDEIROS DE SOUZA, M. F. 0 estudo da coleção de livros da Sociedade dos Cem Bibliófilos do Brasil da Biblioteca Central da Universidade de Brasília. Dissertação de Mestrado. Brasília. 2016.

RIBEIRO, M. E. B. Entre saberes e crenças: o mundo animal na Idade Média. Hist. R., Goiânia, v. 18, n. 1, p. 135-150, jan. / jun. 2013 https://doi.org/10.5216/hr.v18i1.29848

RUFINONI, P. R. Quimeras da Modernidade: uma interpretação da obra Marcelo Grassmann. Tese. USP. 2007.

SOUSA, G. Bestiário. Rio de Janeiro: Sociedade dos Cem Bibliófilos do Brasil, 1957. Gravuras de Marcello Grassmann. 


\section{Sobre o autor}

Matheus Silveira Furtado é formado em Museologia pela Universidade de Brasília, possui licenciatura em História e Mestrado em Artes também pela UnB. É curador e pesquisador pelo Programa de Estudos Medievais - PEM/UnB, seu principal foco de estudo são as representações medievais na contemporaneidade; realizou pesquisas em Instituições como o Museu de Cluny (Paris) e o Instituto Ricardo Brennand (PE), acerca das relações entre os Museus, seus discursos e a Idade Média.

Orcid: https://orcid.org/oooo-0002-2561-3554

Recebido em: 24-08-2020 / Aprovado em: 23-10-2020

\section{Como Citar}

FURTADO, M. S. (2020) O Gravador, a Preguiça e o Viajante. Revista Estado da Arte, Uberlândia. v.1, n.2, p.323-335, jul./dez. 2020. https://doi.org/10.14393/EdA-v1-n2- 2020-56920 